\title{
L'esprit d'Assise. Discours et messages de Jean-Paul II à la Communauté de Sant'Egidio
}

Paris, Le Cerf, 2005, 203 p.

Salvatore Abbruzzese

\section{CpenEdition}

\section{Journals}

Édition électronique

URL : http://journals.openedition.org/assr/3510

DOI : 10.4000/assr.3510

ISSN : $1777-5825$

Éditeur

Éditions de l'EHESS

Édition imprimée

Date de publication : 1 mai 2006

Pagination : 147-299

ISBN : 2-7132-2092-0

ISSN : 0335-5985

\section{Référence électronique}

Salvatore Abbruzzese, "L'esprit d'Assise. Discours et messages de Jean-Paul II à la Communauté de Sant'Egidio », Archives de sciences sociales des religions [En ligne], 134 | avril - juin 2006, document 134-30, mis en ligne le 05 septembre 2006, consulté le 21 septembre 2020. URL : http:// journals.openedition.org/assr/3510 ; DOI : https://doi.org/10.4000/assr.3510

Ce document a été généré automatiquement le 21 septembre 2020.

(c) Archives de sciences sociales des religions 


\section{L'esprit d'Assise. Discours et messages de Jean-Paul II à la Communauté de Sant'Egidio}

Paris, Le Cerf, 2005, 203 p.

\section{Salvatore Abbruzzese}

1 La communauté de Sant'Egidio, fondée à Rome en 1968, constitue l'arrière-fond de ce travail réalisé par Jean-Dominique Durand et manifestement destiné à un public motivé par l'importance de l'engagement pour la paix et le dialogue interreligieux. En effet, ce livre présente une des initiatives principales réalisées par la communauté: les rencontres internationales « Hommes et Religions » animées depuis 1987. L'histoire de ces rencontres fait l'objet de la longue introduction et sert aussi à expliquer l'un des aspects essentiels de la communauté de Sant'Egidio : celui d'un mouvement qui veut se définir par son engagement dans le dialogue interreligieux et pour un monde pacifié : ces deux aspects étant fortement imbriqués l'un à l'autre.

Dans sa deuxième partie, le livre présente les dix-huit « appels à la paix » prononcés par Andrea Riccardi à l'occasion de chaque rencontre. C'est là, dans cette série de messages courts, que le livre veut remettre au lecteur sa documentation essentielle mais, par là aussi, révélatrice : Sant'Egidio, mouvement de prière et de solidarité aux marginaux est aussi, et surtout, dans sa présence organisée, un mouvement de présence sociale se consacrant au dialogue interreligieux et au combat pour un monde pacifié. La troisième partie, contenant les discours et messages de Jean-Paul II à Sant'Egidio, acquiert dans ce contexte une double fonction. D'une part, elle montre la pleine reconnaissance de cette initiative par l'autorité religieuse, de l'autre, elle permet aussi de relever les spécificités du discours pontifical.

3 Les « rencontres pour la paix » s'inscrivent à la suite de la "prière pour la paix » promue par Jean-Paul II à Assise, le 27 octobre 1986. L'introduction fournit suffisamment d'informations pour nous permettre d'observer, quasi «in vitro », le processus de reproduction culturelle d'un événement - celui de la «prière pour la paix " - et sa croissante stabilisation aux fins d'un engagement périodique et 
permanent autour d'un dialogue interreligieux ayant la paix comme objectif et le respect des différentes religions comme méthode.

4 L'événement initial, voulu par Jean-Paul II, devient, via la communauté de Sant'Egidio, un rendez-vous annuel constamment mis à jour qui semble véhiculer, tout d'abord, la revendication d'une filiation (p. 11) se traduisant par une image "l'icône d'Assise », et s'appuyant sur une validation institutionnelle (p. 21) dont les messages de Jean-Paul donnent la preuve. Il semble aussi vouloir s'inscrire dans une mémoire récente, en consolidant un discours longtemps mûri à l'intérieur de l'Église catholique (p. 23). Par là, la reprise de l'initiative pontificale produit aussi un discours, une «théologie d'Assise » (p. 19) ainsi qu'un "mouvement spirituel» signalé par un "pèlerinage annuel » dans des villes-symboles (p.49). Par ce biais, le passage de l'événement à sa répétition annuelle est non seulement la production, toujours reprise et réélaborée, du discours de la paix dans la société globalisée, mais l'élaboration progressive d'un rituel fondé aussi bien sur la reconnaissance des différences, que sur la prière pour des objectifs communs (p. 56).

Le sociologue ne manquera pas de voir ici un processus de structuration visant à régulariser l'événement initial jusqu'à en faire un lieu spatial et temporel au sein de la vie des communautés ecclésiales. La paix est là non seulement l'occasion d'animer une rencontre et d'alimenter un débat, elle est au cœur de la communauté de Sant'Egidio. Le discours sur la paix devient le pôle d'attraction de la communauté en tant que telle.

6 Mais la communauté de Sant'Egidio, telle qu'elle apparaît dans la présentation de l'auteur et dans les mots du fondateur se veut aussi le rapporteur et le collecteur du discours globale sur la non-violence, le respect de l'autre, la légalité foisonnant aussi (et, parfois, surtout) dans le champ laïque. L'inscription dans une mémoire cible moins l'univers catholique que celui de la laïcité : le choix de villes où les rencontres se tiennent, loin de se limiter aux lieux de la mémoire religieuse de l'Europe (Aix-laChapelle) tient à souligner une sorte de nouvelle géographie de la spiritualité européenne où, à côté des villes "symboliques du point de vue religieux " (Rome, Assise, Milan, Jérusalem), sont touchées les villes « symboles de la guerre, du conflit et de la souffrance " (Palerme, Bucarest) passant par les villes de la "paix retrouvée » (Varsovie) et de la réconciliation (Florence, Bruxelles). Finalement, le mouvement se veut le promoteur d'un positionnement du religieux dans la société contemporaine qui en fait l'instrument principal pour une interprétation des souffrances, ainsi que pour un engagement radical pour la réalisation des désirs de paix et de réconciliation.

$7 \quad$ C'est donc un texte à plusieurs entrées que nous propose J.-D. Durand, constitué par des documents et des analyses, par des prises de position et une tentative de les situer dans le plus ample contexte contemporain, et qui est tout à fait révélateur d'un des positionnements possibles des mouvements religieux dans la société contemporaine. 